\title{
Collaborative energy visioning under conditions of illiberal democracy: results and recommendations from Ecuador
}

\author{
Eduardo Noboa $^{1 *}$ D, Paul Upham ${ }^{2}$ and Harald Heinrichs ${ }^{1}$
}

\begin{abstract}
Background: Sociotechnical transitions require pressure to be exerted from inside or outside of the prevailing 'regime', without which various path dependencies combine to maintain the status quo. Change agents including policy entrepreneurs within the regime, or civil society voices outside, can be sources of such pressure. However, in illiberal democracies or authoritarian regimes, these voices may be little heard or even suppressed. With the premise that this situation calls for protected transition spaces for policy development that are outside of formal institutions, so that policy windows may be taken advantage of should they arise, this paper applies a transdisciplinary transition management arena (TTMA) process (Noboa and Upham, Energy Res Soc Sci 46:114-124, 2018), whereby civil society and other stakeholders can be engaged in the envisioning of new energy futures.

Results: With an example of such an arena in Ecuador and presenting a rationale and design that draws on transdisciplinary research and transition management theories, problem statements, visions and strategies for a more decentralised energy system were set out, as generated by participants from government, NGOs, business and academia. The visioning process was evaluated and an analytical framework is proposed, by which to guide energy transition policy analysis in similar contexts in the future.

Conclusions: Although compromised in illiberal democracies, sociotechnical transitions benefit from the voices of change agents through the building of new alternative discourses, stimulating policy entrepreneurship and crafting readiness for policy windows. The new alternative energy visions that were produced by participants in the process described here emphasise distributed renewable and sustainable generation, decentralised decision-making at subnational level, participatory energy planning governance and heterogeneous poly-technological solutions at small and medium scales.
\end{abstract}

Keywords: Ecuador, Illiberal democracy, Transition management, Transdisciplinary research, Energy visions

\section{Highlights}

- Selected concepts from transition management and transdisciplinary sustainability science are blended

- The consequent transdisciplinary transition management arena is applied to the Ecuadorian energy system

- Marginalised voices in Ecuador produced an energy vision emphasising decentralised renewables with temporary large hydro base load

\footnotetext{
* Correspondence: eduardo.noboa@leuphana.de

${ }^{1}$ Institute for Sustainability Governance (INSUGO), Leuphana University

Luneburg, Universitätsalle 1, 21335 Luneburg, Germany

Full list of author information is available at the end of the article
}

- Participants assessed the transdisciplinary transition management arena as performing well in terms of relevant criteria

\begin{abstract}
Background
'Energy visioning' is generally understood as the development of qualitative, energy-focused scenarios, often on a participatory, socially inclusive basis and taking the form of storylines, narratives or other more specific formats [1]. Visioning processes can complement energy planning processes and techno-economic modelling post-hoc or ex-ante, using model results, or can shape modelling according to differing, explicitly normative
\end{abstract}


possibilities, such as alternative levels of consumption or patterns of economic production.

The aim here is to explore the application of a transdisciplinary transition management arena (TTMA) framework whereby multi-sector stakeholders may be meaningfully engaged in the co-construction of new energy futures [2]. The study tests the application of a theoretically grounded rationale for TTMA, particularly under conditions of illiberal democracy in Latin America. That is, whereby civil society and other entrepreneurial but marginalised voices may be empowered through the provision of structured 'experimental' fora or platforms in which new networks can be forged, knowledge shared and generated and alternative policies developed. The process is premised on theoretical perspectives that relate to both theory and method. Regarding the first, the TTMA draws on theories of sustainability transitions and transformation, including transition management. For methodological insights, it draws on ideas from transdisciplinary sustainability sciences and action research. For empirical application, the process is applied in the country of Ecuador. The framework and its use in practice have strong commonalities with transition management and transdisciplinary sustainability science processes characteristics, but the rationale is quite different, a key objective being to demonstrate the value of both approaches for other political contexts.

The study gives equal emphasis to the sociotechnical sustainability transitions literature and the transdisciplinary sustainability science (research) literature, approaching these from an action research perspective in order to co-produce actionable knowledge. In so doing, another underlying premise is Kingdon's theory of policy change via the conjunction of a policy problem with a political window of opportunity for change, with a policy ready to be enacted [3-5]. The framework that we apply here is intended to prepare for such policy windows, should they arise, by providing a protected space for energy policy innovation [3]. The applied and assessed process is unofficial and informal in the institutional sense: the focus is on how informally instituted governance processes might lay the ground for subsequent, formal change through empowering network actors, strengthening their network and (as said) preparing alternative policy for readiness in case of opportune policy windows arising, as shown in Fig. 1 [3]. In this way, we aim to create informal institutions and networks away from the domination of vested interests.

Transition management advocates 'experimental' fora in which possibilities for sociotechnical change can be explored among multi-sector stakeholders [6]. The approach responds to the way in which sociotechnical systems are complex and adaptive [7,8], and the way in which transitions management seeks to guide transition processes via experiments and collaborative visioning, coupling this with participatory futures or scenario design processes. Often the latter involves the use of back-casting methods (e.g. [9]) to identify pathways that guide the development of niche experiments [10,11].

To date, however, the contexts in which transition management has been applied have predominantly been in developed countries, with relatively well-functioning

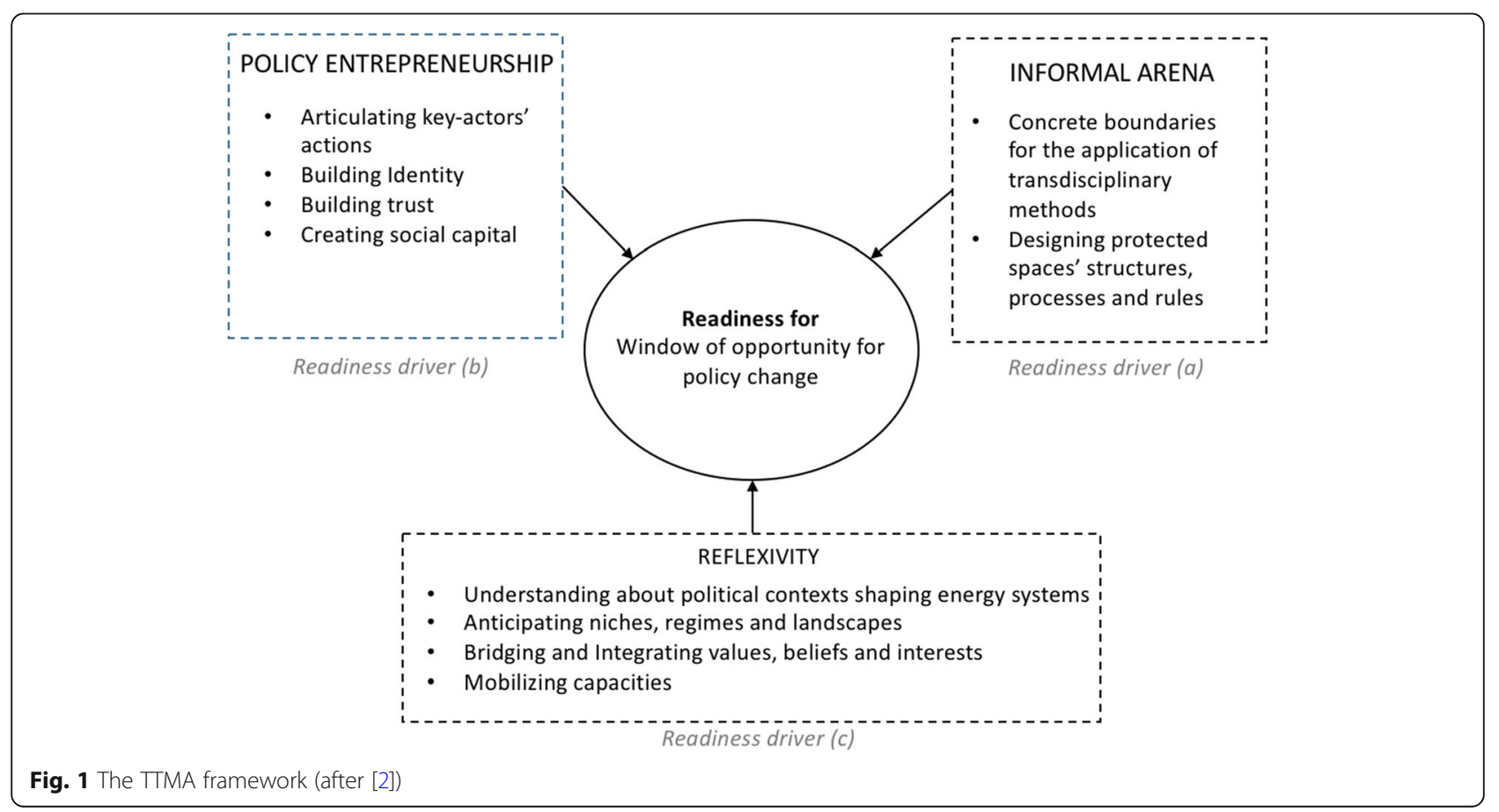


democracies. Here, a forum suitable for supporting multisector energy-focused sociotechnical change in Latin America is developed and discussed. Latin America has experienced political conditions in recent decades substantially different from those in Europe, where transitions management ideas were developed. This has implications for the design of transition management processes, as new forms of institutionalisation pose a threat to the incumbent regime [12, 13], which, in conditions of illiberal democracy, can meet with a severe response.

The Ecuadorian context provides a test-bed for the socio-political process of transition management in similar countries where some of the following Ecuadorian characteristics may be present: economic vulnerability due to dependency on oil exports and its fluctuating price [14], oil production approaching a peak, fossil fuel prices being highly subsidised [15], significant potential for the use of hydropower and/or other renewable energy sources [16, 17], high dependence on knowledge and technology transfer processes [18], compromised institutions for social and environmental governance [19] and a highly centralised energy system [17].

With these characteristics in mind, our premise is that empowering civil society and supporting cross-sectoral networking will promote energy system change through the expression of a wider range of values in alternative policy options. Within a sociotechnical frame, alternative visions of the future are conceived of as selection pressures, while associated civic debate and NGO campaigns are conceived of as articulation pressures [20]. In this regard, there can be seen a value in the involvement of academics as facilitators, in effect operating as policy and informal institutional entrepreneurs, helping to catalyse the preparation of alternative environmental policy options [21].

The transition management design tested in this study draws on features of transdisciplinary research, which are intend to develop socially robust solutions for sustainable transitions via mutual learning, social reflexivity, empowerment and the building of social capital [22]. Transdisciplinary research focuses on the integration of the differing epistemics (ways of knowing) used by scientific researchers and practitioners from different disciplines and with different interests. Both approaches share an acknowledgement of knowledge and the generation of new knowledge as a particularly valuable form of social capital and advocate a view of participatory processes as encouraging social learning and empowerment that can lead to practical change $[23,24]$. Accordingly, fora such as the TTMA bring together two allied approaches as a rationale for underpinning niche-protected energy scenario development in the illiberal democracies of Latin America.

The novelty of the study lies in the investigation of the functioning of a forum that blends transition management and transdisciplinary research, in terms of the extent to which this is able to offer new, productive, theoretical and practical policy options in the context of Ecuador. The questions seek to answer concern to the design and functionality of the TTMA framework developed by [2]: how effective such arena is, as assessed in terms of the extent to which compatible visions and actionable knowledge are produced; how satisfied participants were with the process, which is intended to support identification of points of commonality rather than a focus on differences and what lessons there may be for the design of such processes in future.

In terms of the structure, the paper begins with an overview of the energy policy context of Ecuador, contextualised within its political-economic history. Then the theoretical rationale for the transition arena is set out, followed by the case study methods, the results in terms of the energy vision developed through the process and an evaluation, along with recommendations on the design of the analytical framework, intended to guide energy transition policy analysis in similar contexts in future.

\section{Energy and the Ecuadorian political-economic context}

Ecuador's economy operates around the supply of non-renewable natural resources: principally crude oil and to a lesser extent gas and other minerals. In Wallerstein's terms [25], it is one of the 'peripheral' countries which-for some commentators, in neo-colonial fashion [26] - deliver raw materials to the 'central' countries that control trade in finished goods; goods produced with raw materials and labour from peripheral societies and that feed consumer societies [27].

While countries of Latin America have made considerable and varied progress towards democracy, they continue to struggle with conditions of state and institutional capture and limited civil liberties [28]. One of the consequences of a weak civil society is that insufficient attention has been given the environmental impacts of resource extraction and energy supply. The elites that control non-renewable natural resources at the national level (notably the interest groups linked to oil and mining) have developed an articulated network and an institutionality around the extractive industry that involves clientelism, corruption and state capture [29]. The institutional frameworks are based on coalitions made up of networks of actors (also connected to transnational firms), in which powerful sectors of society participate-government, public and private companiesas well as other beneficiaries of the system. Corresponding rules, norms, laws and standards support the stability of this system and help to resist change [30].

A key point in time for Ecuadorian energy policy was 1979, when, after a decade of military dictatorship, Ecuador returned to a nominally democratic system. This had a significant impact on every aspect of national 
governance. Prior to democratisation, formerly nationalistic policies gave way to a political stance that allowed aggressive private, inward investments [14]. Strategic national resources were privatised, including the exploitation of primary energy resources and electricity generation. Crude oil and fossil fuels were given significant incentives for production and trade. The electricity sector pursued a hydrothermal electricity mix, consisting of large scale hydropower and fossil-fuel-based thermal-electric plants $[15,16]$. This period of neoliberalism lasted for nearly three decades, from 1979 until 2007. The period was characterised by instability and political change, extensive economic liberalisation policies, with fiscal austerity and deregulation [31].

In 2008, a new constitution was written. Taking advantage of revenue from oil exports, the new approach intended to return to a state-controlled natural resource management system and the country adopted the objective of making its energy matrix cleaner and more environmentally sustainable [32]. Control of the energy sector passed from a mainly private-owned governed system to a state-owned centralised system [17]. The period 2008 until 2014 has generally been characterised by economic prosperity as a result of high oil prices and the increase of production from mature oil fields in the Amazon. These factors, among others, have further cemented the neo-extractive economic model of the country. The government implemented policies to promote hydropower, and there were failed attempts to boost non-conventional renewable energies [33]. Energy subsidies remained among the highest in the world [15] (having been strengthened during the previous neoliberal period), which inter alia has led to the transport sector becoming the fastest growing sector of the economy in terms of energy consumption [34]. Despite the sustainability aspirations of the reforms, Ecuador both exports crude oil and imports fossil fuels [35].

The concept of 'energy matrix change' or 'energy transition' has legitimised the new energy policy by promising a gradual increase of the share of renewable energy $[15,16]$. This increase of renewables is intended mainly to be implemented by the electricity sector, by decreasing fossil fuel-based thermal-electric plants and investing in eight new hydropower plants, the latter funded mainly by the pre-sales of crude oil to the Chinese government [17]. The policy discourse has centred on the idea of funding assets of crude oil into large hydropower plants, in the name of climate change, sustainability and a new post-oil period. Nonetheless, the governance structure of the system has remained centralised, controlled by incumbents.

By 2017, Ecuador was expected to attain $90 \%$ of its electricity generated through renewable energy sources, mainly hydropower [16]. In principle, this objective might secure a sustainable energy supply for industrial innovation. However, state indebtedness capacity has reached its limit, oil prices have fallen and these have proved significant barriers to the industrial transformation intended to diversify export commodities and reduce the country's dependence on oil. Moreover, large scale hydropower is highly contentious for its environmental and social externalities [36]. The further centralisation of energy production also threatens to supress the development of other renewable options for decades, stifling diversification, flexibility and local resilience.

\section{Methods}

The research design is consistent with the objectives of producing and evaluating a TTMA capable of producing actionable, policy-relevant knowledge for the redesign of the energy system in an illiberal democracy context. In terms of methods, firstly the capacity of the arena to support the co-production of energy policy visions and strategies was documented. Then, evidence on the effectiveness of the arena from the perspectives of the participants is provided.

\section{Rationale for specific design features}

In terms of evaluative criteria based on the goals of transition management and transdisciplinary sustainability science, the arena should enable the convening of an empowered constellation of change agents, from different sectors, to co-produce transformative knowledge (including end-state visions), build transformational leadership capacities and jointly contribute to the development of policy options for changing the energy system. It is hypothesised that such knowledge may be of most use and influence at times when policy windows occur [3]. As such, the group and its facilitator(s) may be viewed as policy entrepreneurs [21] following a strategy of preparedness for the combination of elements that [3] suggested are prerequisites for policy change. The latter are namely the conjunction of (a) pre-prepared policy option(s), (b) a problem that fits the pre-prepared policy options or perceived solution(s) and (c) political conditions conducive for change (i.e. the conjunction of three multiple policy streams). The approach reflects particular, pre-identified roles of policy entrepreneurs: coalition building, network management and preparation for windows of opportunity. Figure 2 describes this situation, in which the arena supports the framing of a problem for an agenda opportunity, the creation of a preferred vision for a policy goal and the formulation of collective-action strategies for the opportune implementation in the wider political arena.

The case study country is, as said, Ecuador, as both an instance of illiberal democracy and where the lead researcher has been and is embedded within the national energy policy process in both formally and informally instituted ways. Selection of participants was partly based 


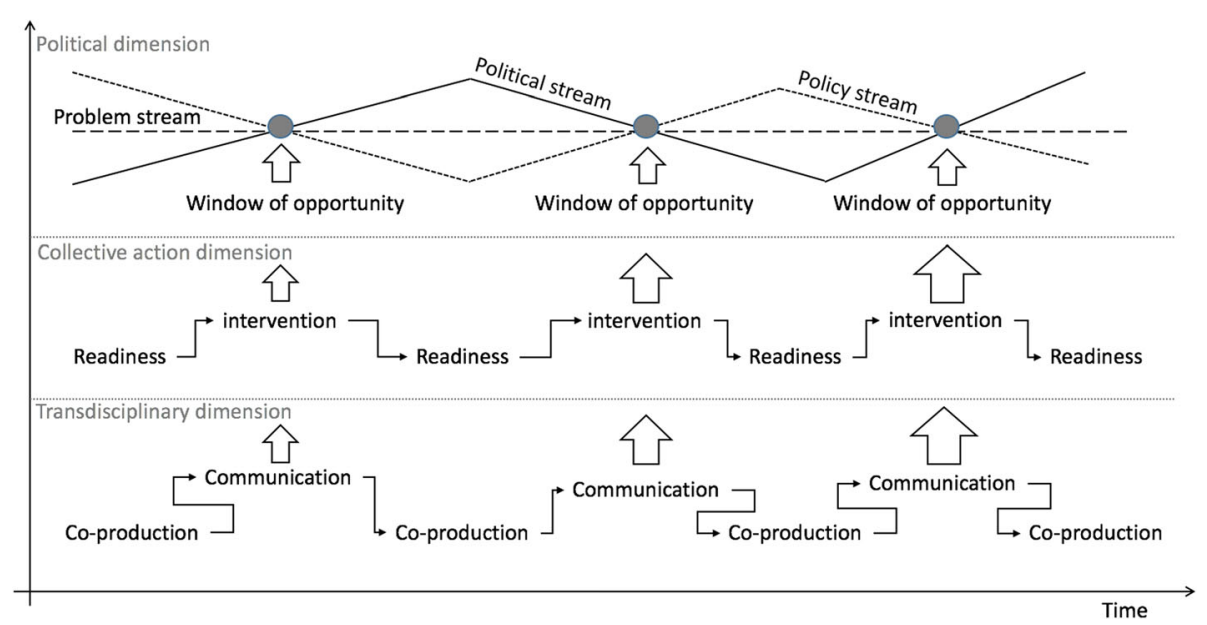

Fig. 2 Synchronising multiple policy streams, collective action and transdisciplinary co-production

on a convenience principle of known contacts but also with the intention of representing different sectors. Table 1 provides the affiliations of individuals involved, who had professional affiliations with 30 organisations, agencies and institutions across the government, society civil and business. Together, they constitute an epistemic community of stakeholders who are professionally engaged with energy policy. ${ }^{1}$

Table 1 Affiliations of participants

\begin{tabular}{ll}
\hline Affiliations & Number \\
\hline Energy ministry & 4 \\
Environmental ministry & 1 \\
Agricultural ministry & 1 \\
Total government & $\mathbf{6}$ \\
Chamber of industry & 1 \\
Renewable energy companies & 4 \\
Consultancy companies & 1 \\
Total business & $\mathbf{6}$ \\
Local universities & 3 \\
International universities & 3 \\
Total academia & $\mathbf{6}$ \\
Regional NGOs & 3 \\
Global NGOs & 4 \\
Professional networks & 1 \\
Total NGOs & $\mathbf{8}$ \\
United Nations Development Programme & 2 \\
Bilateral cooperation & $\mathbf{3 2}$ \\
Multilateral banks & 1 \\
Intergovernmental organisations & $\mathbf{6}$ \\
Total international organisation & $\mathbf{2}$ \\
\hline
\end{tabular}

Participants were guided through a dialogue process, reflecting on and integrating the knowledge held in the group, plus knowledge provided via presentations and policy documents. The first stage was to create a common understanding of the problems of the energy sector-a shared problem statement; the second stage was to anticipate future challenges, bearing in mind global and local dynamics and the third stage to develop a roadmap for future collective actions-specifically, to create visions for the reinvention of the current energy system. These stages are considered in more detail in the "Phases of the arena process" section, and Fig. 2 summarises the objectives of the arena.

Scholz and Steiner [37] distinguish between different types of knowledge in transdisciplinary processes, reflecting different modes of thought, (inter-)disciplinary, perspectives, interests, systems and (organisational) cultures. Figure 3 summarises the types of knowledge involved in such an arena [38], where system knowledge refers to the current state of a system and the key social and other factors involved and the capacity of the system to change [39]. Target knowledge refers to the more specific scope of action and problem-solving measures relating to natural constraints, social laws, norms and values within the system, as well as the interests of actors and their individual intentions [40]. Transformation knowledge refers to the practical implications that can be derived from target knowledge, in respect of changes to existing habits, practices and institutional objectives. Transformation (operational) knowledge enables practitioners to evaluate different problem solving strategies and to achieve the competences to foster, implement and monitor progress and to adapt and change behavioural attitudes [39]. Accordingly, the evaluation takes account of the contribution of transdisciplinary research regarding the differing types of knowledge that are 


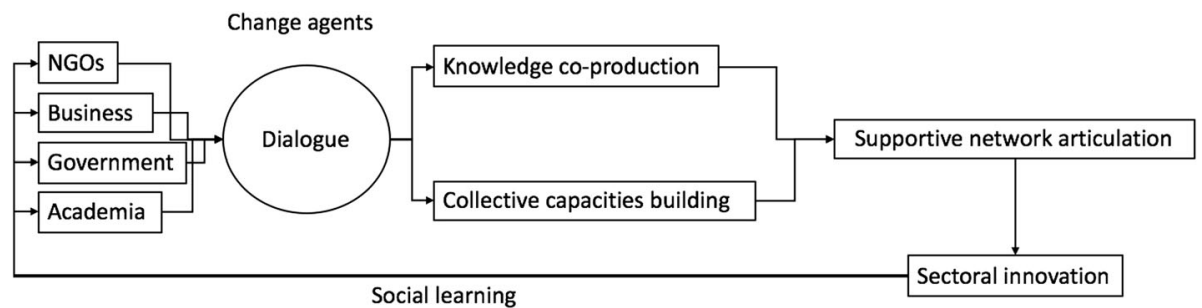

Fig. 3 The objectives of the arena

helpful for such processes and how capacity building takes place through providing opportunities for shared reflexivity and trust-building. Such processes are intended to take place alongside those of formal institutions, generating alternative policy solutions via the involvement of multiple partners and scientific assistance [19] (Fig. 4).

The arena design is intended to encourage reflexivity as part of consensus building, following [41]. That is, to support critical reflection on participants' values and orientation as well as the ability to adapt one's own positions and goals, thereby supporting and enabling capacities for purposive, collective action [42]. This in turn is theorised to involve and develop the capacity to anticipate problems and integrate knowledge, helping to generate the relevant forms of knowledge described above. Figure 5 describes this development of collective capacities.

Another objective of the arena is to promote trust and long-term collaboration among the participants (individual and institutional), resulting from common understandings of the problem, the identification of a shared values and the commitment to organise joint future actions. Figure 6 places these in relation to each other in order to build supportive networks and social capital. Group identity formation is important in engendering a commitment to collective action; hence, [43] refer to the psycho-social normative alignment model of promoting ongoing commitment to collective action via the crafting of a social identity based on norms for emotion, efficacy and action that contribute to a dynamic system of meaning and hence commitment to a cause. Similarly, [44] refer to social identity as shared and relational and as the product of a group's collective history and present. A shared identity also implies a need for trust building. Harris and Lyon [45] observe that trust among stakeholders is shown to be built by having information on others, prior experience of working together, norms of cooperation and sanctions exerted on those who might transgress norms of behaviour [45].

\section{Phases of the arena process}

The phases of the arena process were sequenced so as to support the above processes and either generate or use particular types of knowledge.

\section{(i) Contextualization (information inputs)}

The contextualization phase firstly provides information on the global and national context of the energy sector, and secondly, provides information on the background, objectives and the process of the arena. This included presentations by experts and local authorities about their views of the energy sector's development towards the future.

(ii) Problem definition

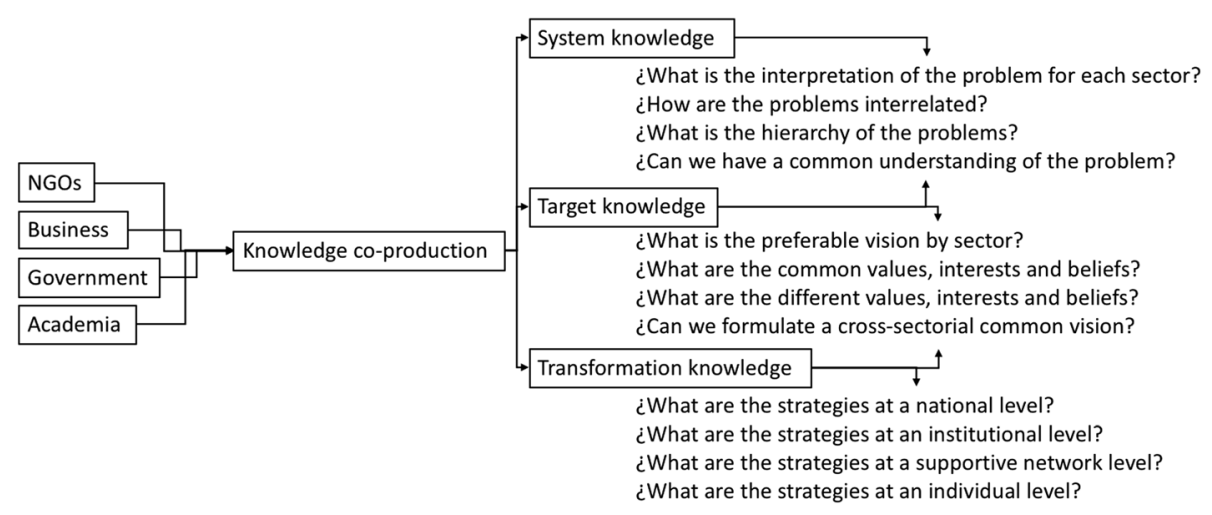

Fig. 4 Co-production of knowledge 


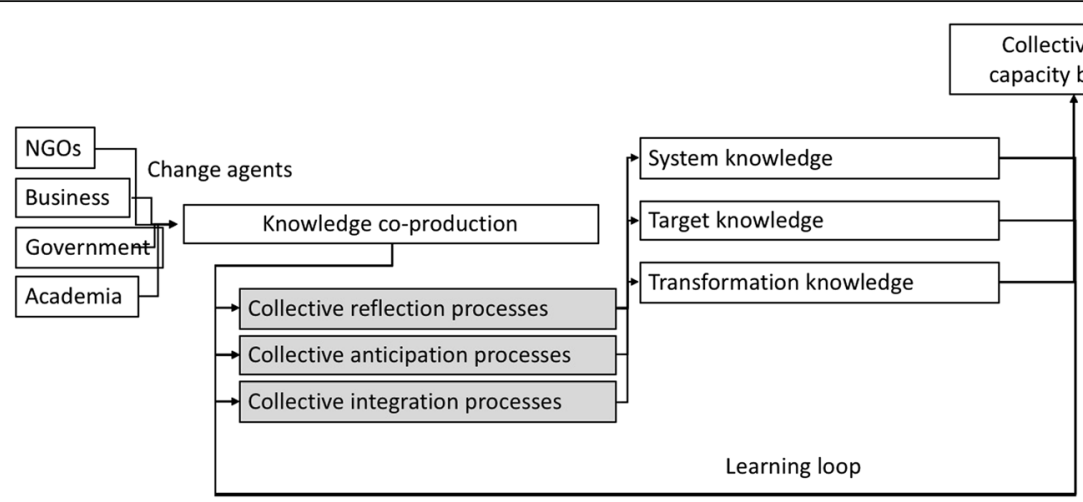

Fig. 5 Development of collective capacities

Generating knowledge of the problem was based on a descriptive analysis of the problems of the Ecuadorian energy sector, investigating the lessons from the past and the present, taking into account the perspectives, concern and experience of the different actors. A common understanding of the problem was created by decomposing the elements that make up the socio-technical-ecological, techno-economic and political subsystems of energy and then discussing how they interact and influence (positively and negatively) the continual reconfiguration of the macro system. The sequence of doing this is described in Fig. 6.

\section{(iii) Vision development}

The generation of multiple visions consisted of a reflective participatory process through which the values, beliefs and interests of the actors, representing the different sectors of society, could be examined within the framework of the collective construction of common visions. Future visions were generated where conflicts and differences were managed via the generation of 'preferable' solutions instead of 'perfect' solutions. These used the system knowledge co-produced in phase 2. Key elements and their interrelationships were identified, taking into account the variety of perceptions and how their arguments and reasoning may be contrary or complementary to one another. This process allows participants to identify spaces of consensus whilst emphasising the creativity and experimentation of a reflexive governance process. The development of visions took place in sectoral groups (government, business, academia, NGOs), where each sector had the task of exploring a future scenario in which the most relevant current issues can be solved, proposing a 'preferable' vision of the future of sustainable energy in Ecuador. These were then presented to the other sectors, in order to generate new perspectives, facilitate understanding and the co-production of knowledge. Figure 7 illustrates the process.

\section{(iv) Strategy development}

The collective production of knowledge about strategies consisted of the formulation of the potential strategies needed to achieve the normative vision proposed in phase 3. Strategies represented the path or roadmap to be followed, taking as orientation the changes required in the elements, subsystems and dynamics to hypothetically achieve a restructuring of the system as a whole. The collective production of transformation knowledge is embodied in the formulation of potential

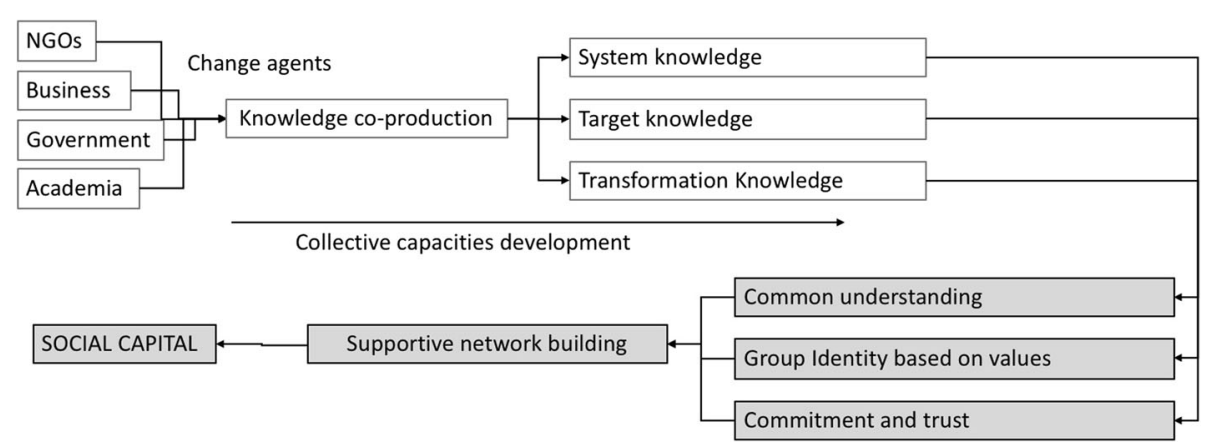

Fig. 6 Supportive network building 


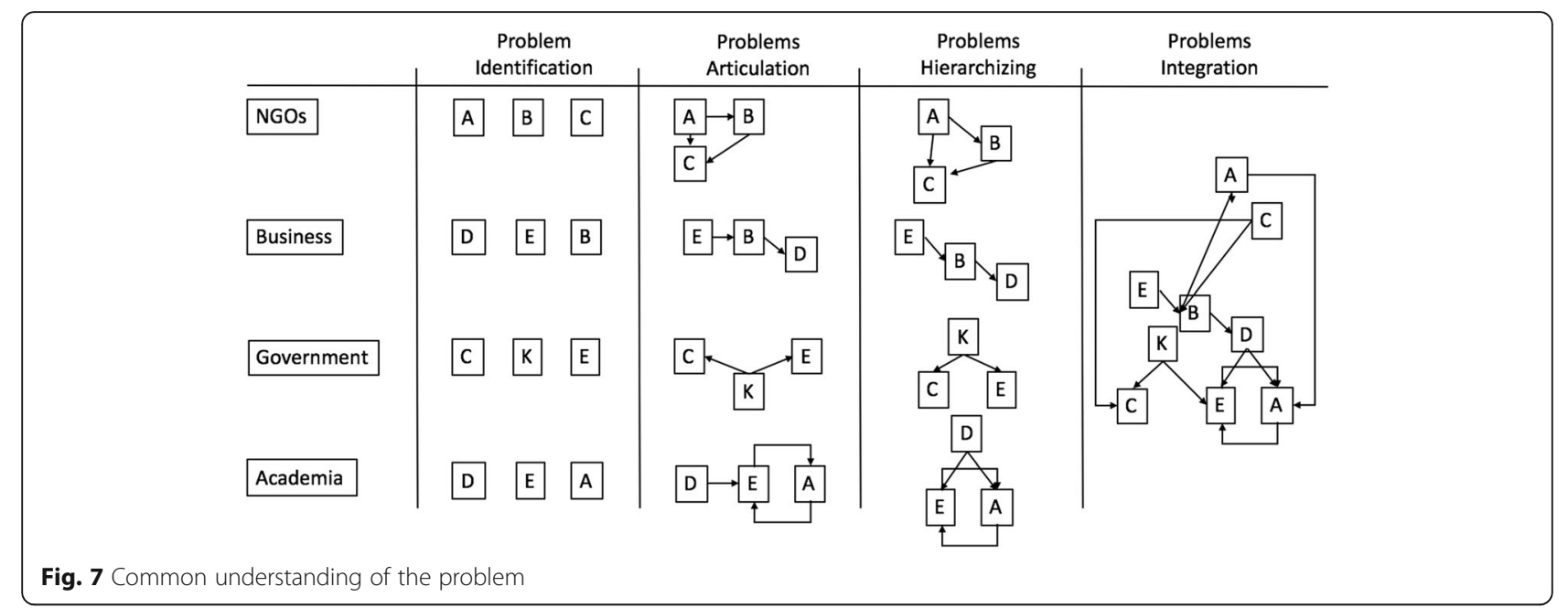

strategies that are needed to achieve the normative vision proposed in phase 3 . The strategies represent a roadmap to guide the actions required to hypothetically stimulate change in the energy system's structure. Figure 8 represents this formulation of multilevel strategies as a collective process of understanding the need for cooperation and linking of the different levels, from the individual contribution, collective action and institutional commitment, to the involvement of decision-makers at a national level.

Through the previous processes of reflection, anticipation of future scenarios and integration of varied perspectives, the participants in the final phase of the participatory process managed to (a) reach a common understanding about the complexity of the energy problem; (b) build a group identity and vision based on common values, beliefs and interests and (c) articulate a group strategy to potentially influence the processes of energy policy formulation. This strategy is enacted through the collaborative generation of knowledge, the construction of an alternative discourse and the strategic cross-sectoral actions which promote transformation towards a sustainable energy system.
In terms of potential windows of opportunity, the arena was implemented between the first round of presidential elections and the second round of presidential elections and in general, such junctures offer situations of policy uncertainty during which alternative policies may find a receptive audience. Another advantage of undertaking this during or close to election periods is that governmental actors who are normally empowered and indeed authoritarian are temporarily in a situation of uncertainty and more inclined to engage with those who are normally disempowered. In other words, they are more open to dialogue with stakeholders and power asymmetries are temporarily reduced. Figure 9 provides additional detail on the wider political juncture relevant during the period of the study.

Regarding data collection and analysis, firstly, ex-ante interviews with the participants were conducted and transcribed; secondly, silent observers recorded and observed the arena process and finally, a post-hoc questionnaire was administered. Themes and issues identified during the session informed the tables and

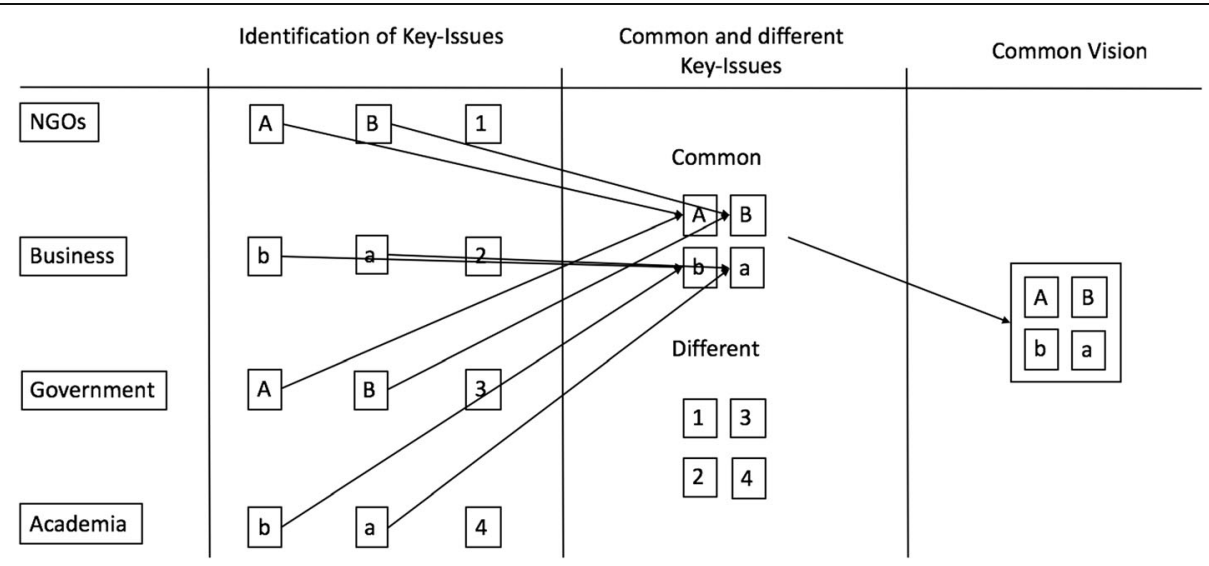

Fig. 8 The development of visions in initially separate groups 


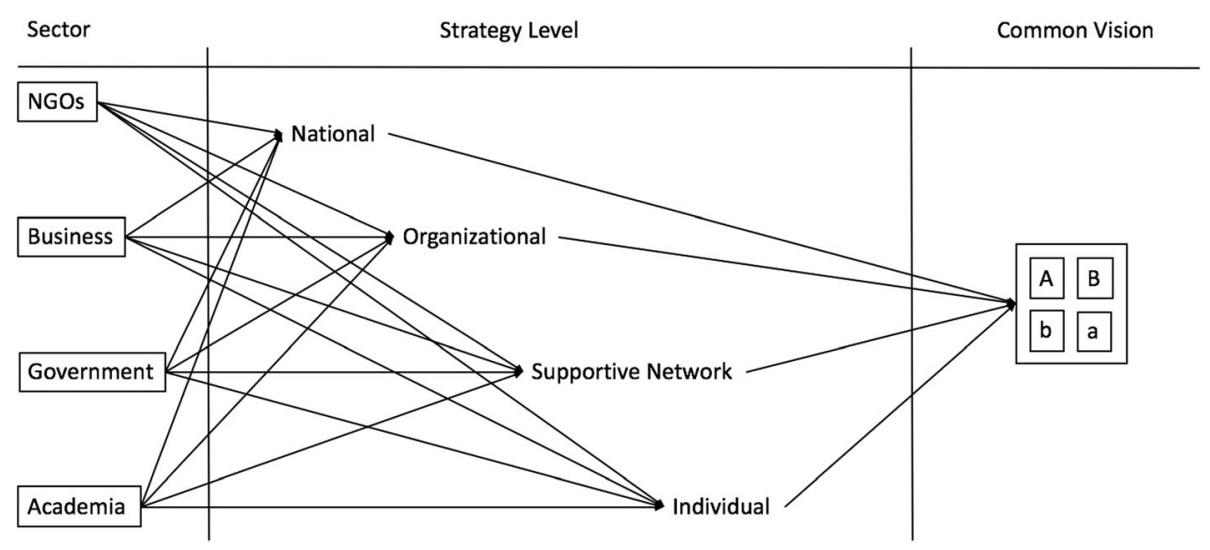

Fig. 9 Formulation of multilevel strategies

framework below, and further reflection was undertaken via thematic coding of the transcripts in qualitative data analysis software Atlas TI (Fig. 10).

\section{Results}

Given our objectives of trialling and evaluating a process, as well as making recommendations regarding any refinements of that process, the results relate to both content and process. The content-based results consist of a conceptual model of the energy system; as it currently is a preferred, long-term vision and a strategy for its implementation.

\section{Process and content}

Overall, the arena design supported joint cross-sectoral and inter-organisational effort, enabling the visualisation of alternative futures and the development of policy strategies for realising these. The arena also facilitated a better understanding of the positions held by those in the different sectors, supporting solution-oriented approaches that are complementary rather than competing, based on a common understanding of the current energy problem that included the perspectives and concerns of the different sectors of the society involved. Table 2 summarises this, alongside perceptions of the key features (right hand column) and problems (centre column).

The results presented are a summary and synthesis of perspectives of the different stakeholders on the participatory process. As can be seen in Table 2, the current development path is viewed as over-reliant on a small number of large hydropower plants, with limited opportunity for diversification into other forms and scales of renewable energy supply that might reduce the vulnerability of the power grid, reduce socio-environmental impacts and catalyse new initiatives among small- and medium-sized companies. In terms of ownership, there is a preference for the private sector to have a role, but not to the extent that state monopoly becomes private monopoly or oligopoly: it is diversity that is sought, for its presumed resilience and dynamism.

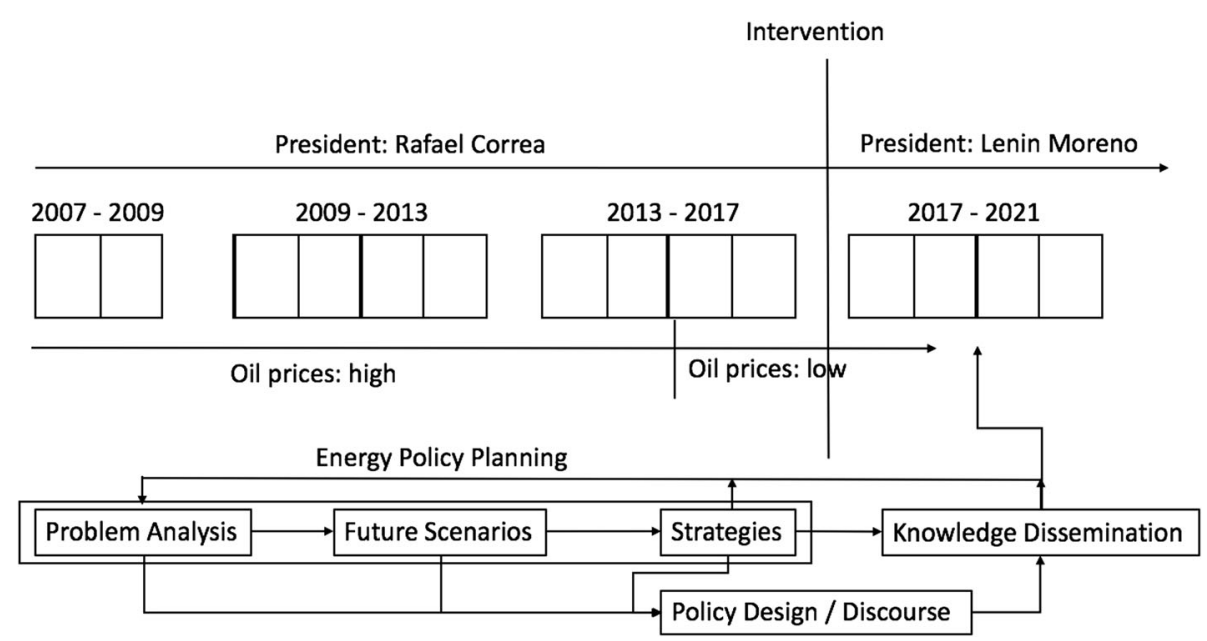

Fig. 10 Window of opportunity by design, presidential elections, new cycle of energy policy planning 
Table 2 Shared understanding of current energy system problems and a future vision

\begin{tabular}{|c|c|c|}
\hline Categories & Sub-categories & Problem \\
\hline \multirow[t]{4}{*}{ Energy planning } & $\begin{array}{l}\text { Interconnection with } \\
\text { national development } \\
\text { plan }\end{array}$ & $\begin{array}{l}\text { No interconnection with the national sustainab } \\
\text { plan }\end{array}$ \\
\hline & Planning horizon & Short/middle political terms planning \\
\hline & Planning goal & $\begin{array}{l}\text { Only focus on electricity/short term: 90\% hydropo } \\
\text { in } 2017\end{array}$ \\
\hline & $\begin{array}{l}\text { Regional integration } \\
\text { approach }\end{array}$ & $\begin{array}{l}\text { National sovereignty: protectionism/competiti } \\
\text { with neighbour countries }\end{array}$ \\
\hline \multirow[t]{3}{*}{$\begin{array}{l}\text { Enabling } \\
\text { environments }\end{array}$} & Financial mechanisms & $\begin{array}{l}\text { Only public investments with international } \\
\text { Chinese loans and multilateral credits are } \\
\text { directed to centralised extractive projects }\end{array}$ \\
\hline & $\begin{array}{l}\text { Knowledge production } \\
\text { and transfer }\end{array}$ & $\begin{array}{l}\text { Lack of processes of knowledge transfer, } \\
\text { production, research and development }\end{array}$ \\
\hline & Capacity building & Lack of capacities for system transformation \\
\hline
\end{tabular}

Technology and infrastructure Regulatory
frameworks

\section{Institutional} framework

Cultural change
Technological diversification in the supply

Energy conversion

Demand/consumption

Ownership of the infrastructure

Supply subsidies/ incentives

Demand subsidies/ incentives

Market access

Degree of centralization Centralised and top-down

in decision making

Market structure
Cross-sectoral integration
Institutional networks
structure

Governance type

Civil society role

Education

Mindset change

Consumer behaviour
Low: large hydro-thermal

Promotion of fossil fuel-based refineries and fossil fuel-based infrastructure

Fossil fuel-based technology use

State-owned

Fossil fuel subsidies and traditional electricity subsidies

Incentives for the use of fossil fuels

No regulations that incentivize the participation of private sector in the supply of renewable energy

Mono/oligopolies

Disconnection of sectoral agendas

Formal sectoral networks with disconnected agendas

Authoritarian, state-driven technocratic governance type

Civil society unable to participate in the decisionmaking processes of the energy sector

No nation-wide environmental education programs for the different levels of education

Neither information nor knowledge is regularly disseminated about the changes needed in the energy system.

There is no experimentation with new models of organisation, business and sectoral interaction.

Consumers are not environmentally aware
Vision

of the energy system

Long-term multi-stakeholder visions

Zero fossil fuels in 2040

Regional sovereignty: renewable energy resources complementarity among countries

Private-public partnerships (PPP) attracting international direct investment

Existence of sectoral knowledge production loops. Cooperation between academia, state and industry via knowledge platforms

Existence of sectoral learning loops. Cooperation between academia, state and industry via knowledge platforms

High: small and middle size poly-technological (mainly: hydro-solar + (biomass/waste/wind))

Bio-refineries and renewable power plants are in operation

Electrification of the final uses

Private-public partnerships

Transparent/fair competition between technologies

Incentives for the use of efficient electricity-based technologies

Regulations incentivize the participation of private sector in the supply of renewable energy via feed$\mathrm{n}$ tariffs (FITs) and auctions

Decentralised and centralised: bottom-up, middle-out and top-down

\section{Multi-SMEs}

Mutually consistent and reinforcing policy mixes Informal and formal cross-sectoral networks interacting

Participatory and reflexive dynamic among societal sectors; polycentric

Civil society is supporting decision-making, promoting dialogue, production of knowledge and integrating new perspectives

Society is well educated about environment and sustainability through formal programs for all levels of education

Long-term communication campaigns are disseminating information driving mindset change

Knowledge and social innovation platforms are part of the sectoral culture

Consumers are socially and environmentally responsible in regards to the selection of efficient artefacts and their energy use 
Table 2 Shared understanding of current energy system problems and a future vision (Continued)

\begin{tabular}{|c|c|c|c|}
\hline Categories & Sub-categories & Problem & Vision \\
\hline & & $\begin{array}{l}\text { Consumers are not actively part of the renewable } \\
\text { energy market }\end{array}$ & $\begin{array}{l}\text { Consumers are becoming prosumers (producers and } \\
\text { consumers). Prosumers sell and buy renewable energy }\end{array}$ \\
\hline \multirow[t]{6}{*}{$\begin{array}{l}\text { Agenda } \\
\text { intersection }\end{array}$} & Water-food-energy nexus & $\begin{array}{l}\text { Lack of integration of the political agendas of the } \\
\text { Ministry of Energy with the Secretary of Water } \\
\text { and the Ministry of Agriculture }\end{array}$ & $\begin{array}{l}\text { There are formal and informal fora's where actors } \\
\text { of the three sectors interact and produce } \\
\text { solution-oriented knowledge }\end{array}$ \\
\hline & $\begin{array}{l}\text { Environment/climate } \\
\text { change-energy nexus }\end{array}$ & $\begin{array}{l}\text { Environmental ministry does not have strong } \\
\text { influence on the decision-making process of the } \\
\text { energy planning }\end{array}$ & $\begin{array}{l}\text { Environmental and renewable energy actors from } \\
\text { academia, business sector, NGOs and government } \\
\text { have developed mechanisms for interactions and } \\
\text { decision-making support }\end{array}$ \\
\hline & $\begin{array}{l}\text { Transportation } \\
\text { (mobility)-energy nexus }\end{array}$ & $\begin{array}{l}\text { Transport and energy agendas do not have a } \\
\text { strong interface. Inefficient individual fossil-fuel- } \\
\text { based systems are promoted }\end{array}$ & $\begin{array}{l}\text { Efficient, social and environmental friendly multi-modal } \\
\text { systems are implemented with the support of } \\
\text { participatory planning process involving the Ministry } \\
\text { of Transport, subnational levels (municipalities) and } \\
\text { cross-sectoral stakeholders }\end{array}$ \\
\hline & $\begin{array}{l}\text { Social development- } \\
\text { energy nexus }\end{array}$ & $\begin{array}{l}\text { There isn't an energy social agenda where social } \\
\text { and energy strategies have an interplay }\end{array}$ & $\begin{array}{l}\text { A cross-sectoral energy social agenda is implemented } \\
\text { in order to deal with energy-justice, energy-poverty, } \\
\text { energy-equity and energy-democracy }\end{array}$ \\
\hline & $\begin{array}{l}\text { Productive matrix-energy } \\
\text { nexus }\end{array}$ & $\begin{array}{l}\text { Crude oil is the main export product and will } \\
\text { remain for the next } 10 \text { years until the reserves } \\
\text { decline dramatically }\end{array}$ & $\begin{array}{l}\text { Renewable electricity is fuelling the productive } \\
\text { matrix transformation by electrifying the production } \\
\text { of goods and services for export }\end{array}$ \\
\hline & $\begin{array}{l}\text { International affairs-energy } \\
\text { nexus }\end{array}$ & $\begin{array}{l}\text { Weak regional energy integration processes. } \\
\text { There are no complementarity strategies }\end{array}$ & $\begin{array}{l}\text { Strong energy systems integration processes within } \\
\text { the South American region promoting resources } \\
\text { complementarity }\end{array}$ \\
\hline
\end{tabular}

The participants' views favour micro, small- and medium-scale energy supply at different subnational levels, paralleling the results of the United Nations Habitat III meeting that was held in Quito-Ecuador in 2016, where the need to decentralise energy systems to municipal levels was highlighted [46, 47]. Stakeholders were similarly concerned about the lack of development of the microgeneration and/or distributed generation to date in Ecuador. The linkages between decentralisation and democracy was also a priority within the discussions, where participants pointed out how decentralised infrastructure can strengthen democratic processes and stimulate the distribution of investments, benefits and wealth around the country and at the same time create a nation-wide industrial constellation by supporting and mobilising the capacities of small and medium enterprises currently trying to promote non-conventional renewable energy supply.

Moreover, the participants proposed a future energy matrix that is a hydro-solar mix, where the existing large hydroelectric supply acts as base load, synchronising and coordinating with micro, small and medium solar-photovoltaic systems that would more fully exploit the solar potential of the equator in locations with suitable conditions, as well as residential solar thermal-waterheaters in Amazonian and coastal regions. Other types of non-conventional renewable energy technologies such as biomass (solid, liquid and gas), wind and geothermal were also consider as part of a preferable future scenario that would replace fossil-based sources at a progressive pace.
The energy matrix diversification according to the participants would, overall, reflect heterogeneous solutions on a multi-level and multi-scale basis, diverse in terms of technologies and plural in terms of decision-making and investment (e.g. public-private partnerships, municipal-private partnerships, etc.). This is reflected in Table 2.

Another key theme in terms of output from the TTMA is the need for attention to the ongoing dependence on and subsidy for fossil fuels in the transport (mobility) sector and residential LPG (liquefied petroleum gas) for cooking and water heating, as well as the lack of policies for encouraging energy efficiency or reduce waste and environmental impacts. The group reflected on the need to reduce and redirect current fossil fuel subsidies towards dynamic incentives that promote renewable technologies in these sectors.

Building on this, participants produced a set of strategies for achieving the vision (Table 3 ). The latter covered topics including integrated planning and political agendas intersection (water-food-energy nexus), decentralisation of infrastructure and decision making, good governance and participative energy planning, diversification of energy sources, demand side management through education, correct endowment of energy subsidies and transparency in prices, the establishment of a zero fossil fuel target, strengthening of energy security and resilience and sustainability of the system, among others.

Figure 11 summarises the interconnections among the elements of the reconfigured system envisaged. 
Table 3 Co-produced strategies for achieving the new energy system vision

\begin{tabular}{ll}
\hline Strategies for energy system transformation \\
\hline $\begin{array}{l}\text { Cross-sectoral participatory } \\
\text { scenario planning }\end{array}$ & To create a common vision about the \\
& future of Ecuador, not only energy. \\
& This vision will guide the shaping of the \\
& energy system \\
& To institutionalise participatory planning \\
& process with long-term visioning \\
& processes \\
& To develop cross-sectoral key-expert \\
& dialogues and participatory planning \\
& workshops about political agenda \\
& intersections
\end{tabular}

Educational strategies for sustainable development

Financial strategies

Knowledge co-production platforms

Regulatory frameworks development for the innovation of the sectoral culture
To develop and articulate educational proposals to be transfer for the implementations by the national authorities

To institutionalise knowledge co-production for the innovation of the sectoral culture

To develop regional expert dialogues and workshops about energy complementarity in order to co-produce knowledge about the energy complementarity in the region

To produce technical robust knowledge about redirecting investment to sustainable alternatives. Divesting carbon and investing in renewability

To develop a regulatory framework proposal to promote legal security and private-public partnerships for investments

To develop a regulatory framework proposal to promote small and middle size poly-technological (mainly: hydro-solar + (biomass/waste/wind)) investments

To incentive the use of electricity-based alternatives. Creating awareness of the need to eliminate fossil fuel subsidies and incentive the use of local renewable energy sources

To institutionalise knowledge co-production

To develop regional expert dialogues and workshops about energy complementarity in order to co-produce knowledge about the energy complementarity in the region

To produce technical robust knowledge about redirecting investment to sustainable alternatives. Divesting carbon and investing in renewability

To develop a regulatory framework proposal about sustainable energy pricing policies

To develop a regulatory framework proposal to incorporate future participation of private companies in the process of energy supply

To develop a regulatory framework proposal to incorporate future participation of private SMEs companies in the process of energy supply
Table 3 Co-produced strategies for achieving the new energy system vision (Continued)

\begin{tabular}{|c|c|}
\hline \multicolumn{2}{|c|}{ Strategies for energy system transformation } \\
\hline & $\begin{array}{l}\text { To develop a regulatory framework } \\
\text { proposal to promote legal security for } \\
\text { private-public partnerships and investments }\end{array}$ \\
\hline & $\begin{array}{l}\text { To develop a regulatory framework } \\
\text { proposal to promote small and middle } \\
\text { size poly-technological (mainly: hydro-solar } \\
\text { + (biomass/waste/wind)) developments }\end{array}$ \\
\hline \multirow[t]{2}{*}{$\begin{array}{l}\text { Strategic communication } \\
\text { strategies }\end{array}$} & $\begin{array}{l}\text { To develop and implement multi-channel } \\
\text { communication campaigns to create } \\
\text { awareness, understanding, engagement } \\
\text { and action by societal actors }\end{array}$ \\
\hline & $\begin{array}{l}\text { To incentive the use of electricity-based } \\
\text { alternatives. Creating awareness of the } \\
\text { need to eliminate fossil fuel subsidies } \\
\text { and incentive the use of local renewable } \\
\text { energy sources }\end{array}$ \\
\hline $\begin{array}{l}\text { Supportive networks } \\
\text { articulation }\end{array}$ & $\begin{array}{l}\text { To empower cross-sectoral partnerships } \\
\text { of civil society, academia and business } \\
\text { sector by generating and transferring } \\
\text { knowledge and articulating networks }\end{array}$ \\
\hline
\end{tabular}

Figure 12 describes some of the strategies by which the new vision would be reached, encompassing new knowledge co-production and capacity building, networks and coalition articulation and various strategic communication strategies and channels (fostering interface spaces and dialogue, participation and involvement, lobbying, think tanks, policy support, cyber-politics) creating a knowledge and communication loop and a learning and empowering loop.

\section{Evaluation and framework to guide energy transition policy development}

In terms of evaluation, the participants concurred that the transdisciplinary transitions arena succeeded in stimulating socio-professional networks that were likely to endure in the medium to longer term. Nonetheless, there is clearly scope for longitudinal study, to assess any changes in the access to power, changes in discourse and understandings of energy sector problems both in the niche and the political arena. Table 4 presents descriptive statistics for selected process evaluation questions, drawing on over 30 such questions, all inviting responses on a 5-point Likert scale. All show a large majority of positive view.

Based on the above rationale, sequenced structure and effectiveness of the arena in the terms described above, an energy transition assessment framework is proposed as follows in Fig. 12. The purpose of this framework is to aid and guide thinking in similar contexts, building on the experience in Ecuador. It begins with development and planning principles for orientation that draw on the principles of transition management and transdisciplinary (sustainability science) research, particularly those relating to the inclusion of a range of stakeholders in the design of policy and practice for sustainability 


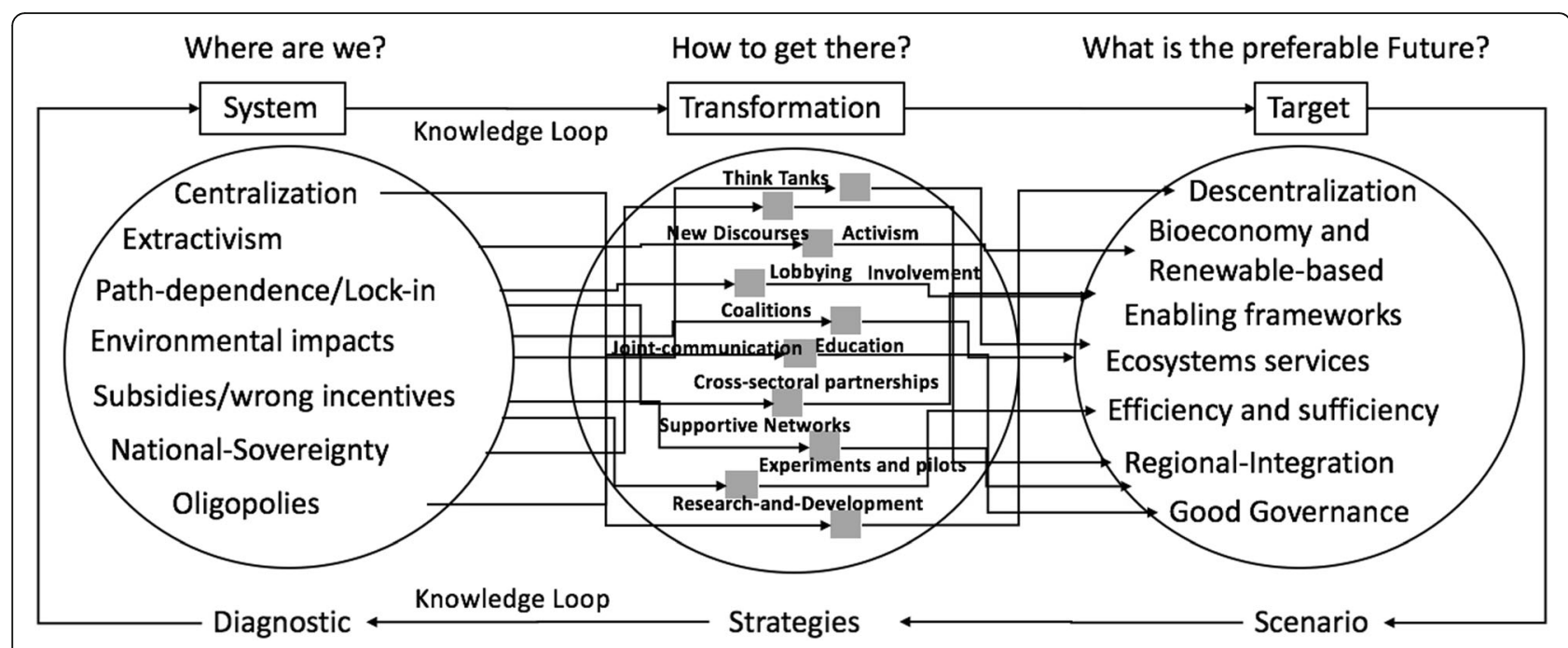

Fig. 11 Detail of interconnections

[48]. It also draws on the knowledge-related principles of transdisciplinary (sustainability science) research, which seeks to incorporate and cohere different types and sources of knowledge [49]. Finally, it draws on the systems perspective of sociotechnical transitions thinking in general, in which the different realms of society (politics, economics, resources, technology, etc.) are viewed as inter-related, mutually influencing and hence requiring policy responses that recognise this [50]. As such, the framework lays out and categorises recommended, core elements for consideration in such arenas (Fig. 13).

\section{Discussion}

Experience with the transition arena in Ecuador raises a number of inter-related issues. These include the normativity of the transitions management, transdisciplinary sustainability science research and the advocated framework, their generalisability and issues of democratic representation, including the role of civil society and other actors, such as lay publics. These issues are considered below.

Within a sociotechnical frame, alternative visions of the future are conceived of as selection pressures, meaning that these visions compete and present alternative options. The associated civic debate and NGO campaigns are conceived of as articulation pressures, meaning that these are means by which pressure is exerted [20]. Transition management arenas are premised on the view that formal institutions are not themselves capable of generating these types of pressure, that is, that they are not supportive of innovative thought, social and policy experiments- nor to widely cross-sectoral engagement. Formal institutions have path dependencies that maintain the status quo, and formally instituted policy change often has implications for resource distribution;

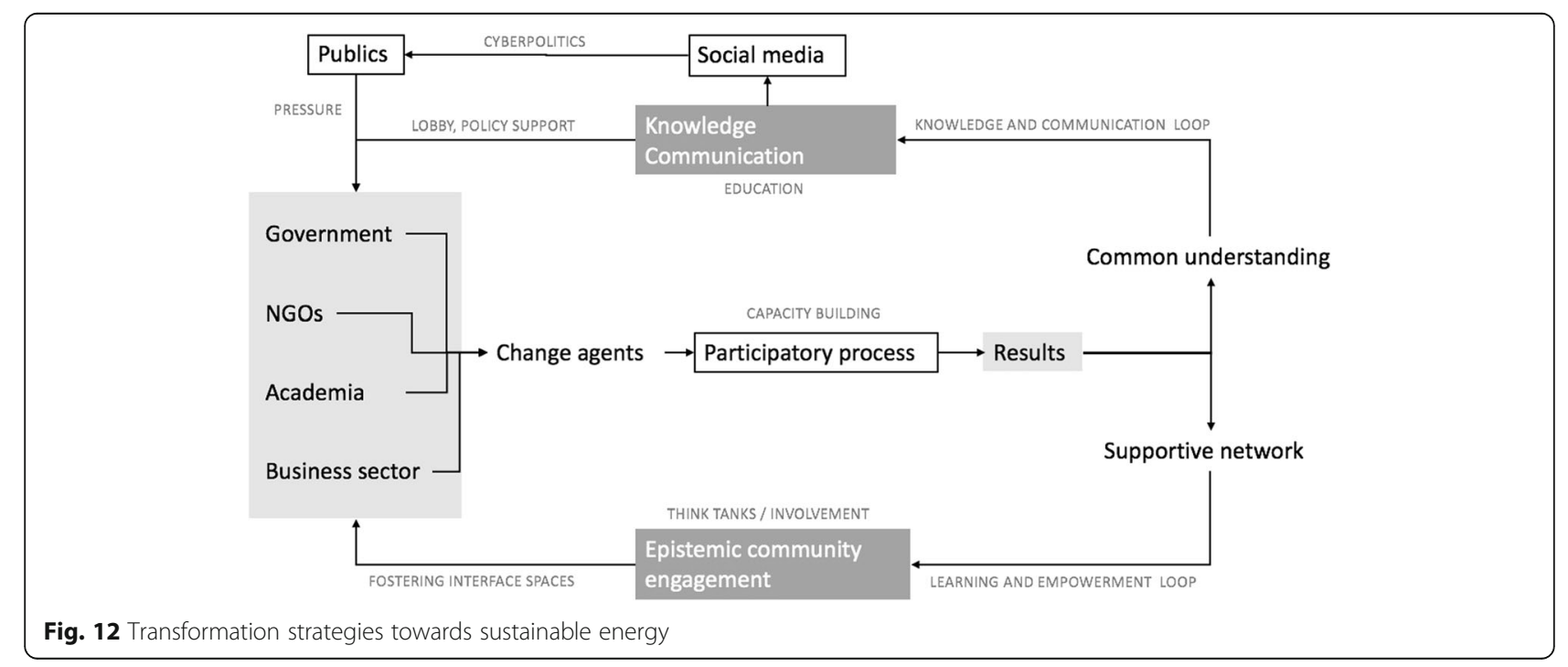


Table 4 Selected process evaluation questions ( $n=30$ participants)

\begin{tabular}{lll}
\hline Question & $\begin{array}{l}\text { Strongly } \\
\text { agree }\end{array}$ & Agree \\
\hline $\begin{array}{l}\text { The knowledge generated is relevant to the current } \\
\text { circumstances. }\end{array}$ & $83 \%$ & $7 \%$ \\
$\begin{array}{l}\text { The knowledge generated contains ideas that question } \\
\text { the status quo. }\end{array}$ & $47 \%$ & $33 \%$ \\
$\begin{array}{l}\text { The knowledge generated helps to understand the } \\
\text { logic between the elements of the system. }\end{array}$ & $37 \%$ & $57 \%$ \\
$\begin{array}{l}\text { The process stimulated self-reflection about my position } \\
\text { (orientation of my values, beliefs and interests) regarding }\end{array}$ & $30 \%$ & $40 \%$ \\
the energy system. & & \\
$\begin{array}{l}\text { The process stimulated the connection of various types } \\
\text { of knowledge and integration of different perspectives }\end{array}$ & $43 \%$ & $37 \%$ \\
on the energy sector. & & \\
$\begin{array}{l}\text { The process encouraged the expansion of my knowledge } \\
\text { about the sustainability of the energy sector }\end{array}$ & $43 \%$ & $27 \%$ \\
$\begin{array}{l}\text { The group dynamics generated a common understanding } \\
\text { of the key elements of the energy problem. }\end{array}$ & $43 \%$ & $40 \%$ \\
$\begin{array}{l}\text { Group dynamics enriched the understanding of the } \\
\text { problem by including new perspectives. }\end{array}$ & $53 \%$ & $37 \%$ \\
$\begin{array}{l}\text { The group dynamics identified elements that can articulate } \\
\text { a sustainable vision of the future of the energy sector. }\end{array}$ & $50 \%$ & $30 \%$ \\
$\begin{array}{l}\text { Group dynamics facilitated the process of developing } \\
\text { strategy proposals to achieve the vision for the future. }\end{array}$ & $33 \%$ & $40 \%$ \\
\hline
\end{tabular}

both features mitigate against change and experimentation. In short, those operating within and dependent on a relatively stable sociotechnical regime are unlikely to seek to destabilise it unless they see some purpose to doing so; it is often the need to respond to external pressures that provide this purpose and motivation.

In illiberal democracies, the stability of the status quo is strengthened by features such as state capture, authoritarianism and monopoly or oligopolistic control. Transition management seeks to intervene and disrupt the status quo in non-confrontational ways; though of course, this may well limit its effectiveness in terms of policy change. Nonetheless, it seeks to build a wider policy legitimacy through relatively inclusive participation and hence perceived procedural legitimacy [51]. As a governance perspective, transition management views the engagement of a wide variety of stakeholders in policy development as a necessary element in furthering sustainability through enhanced social learning $[52,53]$.

The TTMA that is trialled here-and the underpinning, corresponding analytical framework that is advocated-both allow for the explicit definition of particular norms, but only to the extent that these are consistent with the premises of sociotechnical sustainability transitions [54] and transdisciplinary sustainability science research [55]. Within these terms, the framework allows for the expression of different specific norms (e.g. regarding the ongoing use of fossil fuels with carbon capture or large-scale use of biomass and hydropower). As such, therefore, while it can be seen that the TTMA and the proposed analytical framework are somewhat normatively flexible and generalizable, it should be recognised that they do embody norms of liberal democracy.

Moreover, it is also recognised that there are alternative conceptions of sustainability and optimal or preferred sociotechnical routes to similar lower carbon goals. This raises the question of how the arena process, and the framework might accommodate any irreconcilable clash of views within the group. Here, the development of visions deliberately took place in separate sectoral groups (government, business, academia and NGOs), where each sector had the task of developing a future scenario that would address the problems that they perceived as most relevant. These scenarios were then presented to the other sectors, in order to generate new perspectives, facilitate understanding and co-produce a synthesis scenario. This process 'worked' because the invited participants were known priori to share compatible views on how the energy system in Ecuador should develop. This is an important success condition. If participants are unable to generate a consensual vision, then a number of variant visions may be required and this should not (in our view) be seen as problematic.

\section{Conclusion}

A case for the value of blending aspects of transdisciplinary sustainability and transition management, to form a 'TTMA', is advocated, by which to justify and guide the engagement of multi-sector actors in the design of alternative energy futures in illiberal democracies. The rationale for this centres on the premise that outputs from such processes may function as a source of pressure on the sociotechnical regime, should policy windows arise. Here, such a TTMA is described, and its application in Ecuador assessed, with the design being found effective in terms of generating a consensual vision and set of policy-related strategies. A framework for guiding future instances is set out accordingly.

At the same time, it is also clear that such proposals are no panacea for the interconnected political and energy system problems of countries such as Ecuador. Indeed, their location outside of formal institutions can be viewed as a weakness, with no direct input to formal policy processes. Moreover, consensus within such processes cannot always be presumed, especially as policy proposals become more specific. Nonetheless, the development of more than one vision and set of strategies within such contexts is feasible and can be allowed for. Overall, experience with energy-related TTMA outside of developed countries is still limited in extent, and there is significant scope for further empirical and theoretical consideration of how well such concepts transfer to different political and economic contexts. 


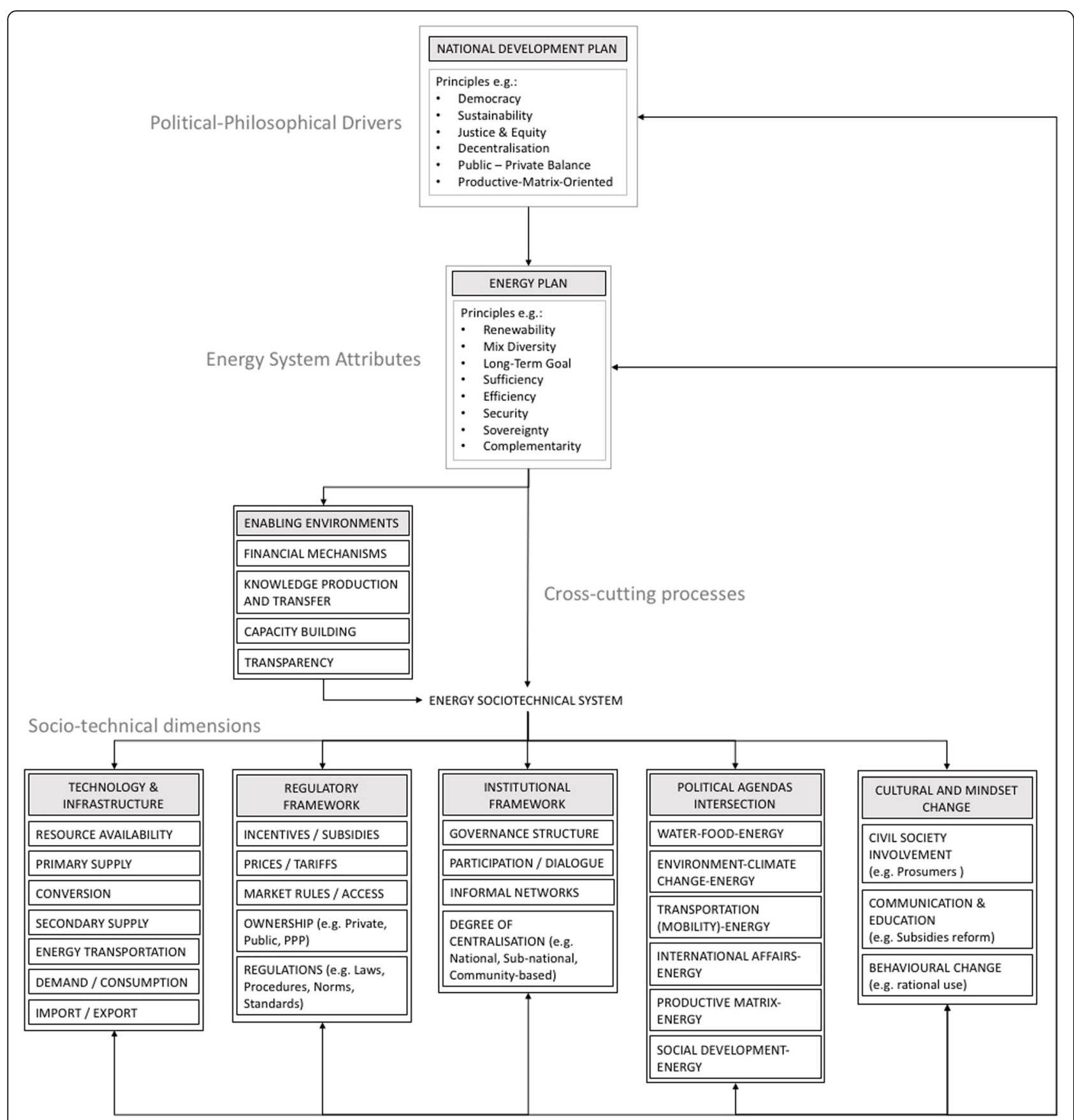

Fig. 13 A framework for energy transition policy

While transition management experiments have been implemented in Europe and interest is growing in transdisciplinary science approaches, use of these rationales for informal energy planning processes in developing countries, where energy sector planning processes are autocratic or technocratic, state-driven centralised or private-driven centralised, reflecting the characteristics of illiberal democracies and state capture, has been less common. Nonetheless, TTMAs arguably have potential for application in Latin American and developing countries, where the conditions permit the parallel development of non-mainstream policy, awaiting policy windows for change. Indeed, the authors have undertaken a similar exercise in Peru, where the political context is governed by the private sector (state capture). The results were similar, though the scenarios and visions involved more small-scale renewables, multi-pole decentralised governance and 
distributed generation; transparency was also given a higher priority. There is also experience of participatory modelling and planning in Chile and Argentina, having been promoted by governments and involving civil society, business and academia [56, 57].

Overall, the originality of the study lies in two main contributions. The first is the combination of transdisciplinary research, transition management and multiple streams approach as a rationale; the second is the practical application, trial and evaluation of the approach in a developing country, specifically an illiberal democracy. It was found feasible to articulate a multi-stakeholder group in order to co-produce knowledge about a common problem, a preferable vision and strategies that are amenable to translation to policies. While a TTMA cannot of course guarantee policy implementation, with institutionalisation or adoption of TTMA output being subject to political and decision processes outside of its control, the TTMA at least offers a preparatory stage for transformation, helping to develop supportive knowledge-networks and alternative discourses, for windows of opportunity.

The implications of the above are primarily in the informal rather than formal policy sphere, given that transition management arenas are specifically intended to mitigate against the path dependencies or lock-ins of formal institutions. As stated, the objective of such arenas is to develop alternative or informal policy that is available for application when circumstances permit. The policy objectives and strategies developed through the arena reflect the principles of transition management, which in turn reflect a systems perspective. Hence, they call for policy mixes that are consistent in the sense of being mutually reinforcing despite being applied in different sectors. They call for a more decentralised and liberalised energy system with a multi-scale renewable energy supply.

Overall, there is a strong theme of opening the energy system up to other possibilities than what current state monopolies permit, while at the same time simply avoiding creating private monopolies or oligopolies instead. These possibilities relate to technology types and scales, institutional frameworks and-importantly-governance arrangements. In an illiberal democracy, the latter is at the heart of the problem and informal policy arenas are an attempt to improve on a situation where too few interests are involved in policy shaping. Going forward, it remains to be seen to what extent Ecuadorian energy policy opens up in all senses.

\section{Endnotes}

${ }^{1}$ This particular arena did not involve members of the lay public. Although a case can certainly be made for doing this, the purpose of the arena was to co-produce primarily scientifically and technically informed policy visions.

\section{Abbreviations}

FIT: Feed-in tariff; LPG: Liquefied petroleum gas; NGO: Non-governmental organisation; PPP: Public-private partnership; SME: Small and medium enterprise; TTMA: Transdisciplinary transition management arena

\section{Funding}

The transdisciplinary transition management workshop was co-funded by the charitable foundation Friedrich-Ebert-Stiftung (FES-ILDIS), the International Union for the Conservation of Nature (IUCN), the Future Latin American Foundation (FFLA) and Leuphana University Lüneburg (Germany).

\section{Availability of data and materials}

The study is semi-qualitative and conforms to the usual norm of maintaining confidentiality for those who took part, rather than hosting data publicly.

\section{Authors' contributions}

EN designed and undertook the research project, including establishing the theoretical framing. PU made a substantive contribution in terms of discussion of ideas and language. $\mathrm{HH}$ also added to the theoretical development of the paper. All authors read and approved the final manuscript.

\section{Ethics approval and consent to participate}

Via an ethical protocol, the participants gave informed consent to the use of information generated in the forum process. Conditions of anonymity have been adhered to.

\section{Consent for publication}

There is no individually identifiable information in the paper.

\section{Competing interests}

The authors declare that they have no competing interests.

\section{Publisher's Note}

Springer Nature remains neutral with regard to jurisdictional claims in published maps and institutional affiliations.

\section{Author details}

${ }^{1}$ Institute for Sustainability Governance (INSUGO), Leuphana University Luneburg, Universitätsalle 1, 21335 Luneburg, Germany. ${ }^{2}$ Institute for Environmental and Sustainability Communication (INFU), Leuphana University Luneburg, Universitätsalle 1, 21335 Luneburg, Germany.

Received: 22 May 2018 Accepted: 20 September 2018

Published online: 08 October 2018

\section{References}

1. Ernst A, Biß KH, Shamon H, Schumann D, Heinrichs HU (2018) Benefits and challenges of participatory methods in qualitative energy scenario development. Technol Forecast Soc Change 127:245-257 https://doi.org/10. 1016/j.techfore.2017.09.026

2. Noboa E, Upham P (2018) Energy policy and transdisciplinary transition management arenas in illiberal democracies: a conceptual framework. Energy Res Soc Sci 46:114-124. https://doi.org/10.1016/J.ERSS.2018.07.014

3. Kingdon JW (2003) Agendas, Alternatives, and Public Policies, 1976, 1977, 1978, 1979 [United States]. https://doi.org/10.3886/ICPSR28024.v1

4. Cairney P, Jones MD (2016) Kingdon's Multiple Streams Approach: what is the empirical impact of this universal theory? Policy Stud J 44:37-58. https://doi.org/10.1111/psj.12111

5. Llamosas C, Upham P, Blanco G (2018) Multiple streams, resistance and energy policy change in Paraguay (2004-2014). Energy Res Soc Sci 42. https://doi.org/10.1016/j.erss.2018.03.011

6. Frantzeskaki N, Kabisch N (2016) Designing a knowledge co-production operating space for urban environmental governance-lessons from Rotterdam, Netherlands and Berlin, Germany. Environ Sci Pol 62:90-98. https://doi.org/10.1016/j.envsci.2016.01.010

7. Foxon TJ, Reed MS, Stringer LC (2009) Governing long-term social-ecological change: what can the adaptive management and transition management approaches learn from each other? Environ Policy Gov 19:3-20

8. Loorbach D (2010) Transition management for sustainable development: a prescriptive, complexity-based governance framework. Governance 23:161-183

9. J. Quist, Backcasting for a sustainable future: the impact after 10 years, 2007 
10. Rotmans J, Kemp R, Van Asselt M (2001) More evolution than revolution: transition management in public policy. Foresight 3:15-31

11. Smith A, Stirling A. The politics of social-ecological resilience and sustainable socio-technical transitions. Ecol Soc. 2010;15(1).

12. Smith, A., Stirling, A., Berkhout, F., 2005. The governance of sustainable socio-technical transitions. Res. Policy 34, 1491-1510. https://doi.org/10. 1016/j.respol.2005.07.005

13. Shove, E., Walker, G., 2007. CAUTION! Transitions ahead: politics, practice, and sustainable transition management. Environ. Plan. A 39, 763-770

14. Svampa M (2015) Commodities consensus: neoextractivism and enclosure of the commons in Latin America. South Atl Q 114:65-82. https://doi.org/10. 1215/00382876-2831290

15. Chavez-Rodriguez MF, Carvajal PE, Martinez Jaramillo JE, Egüez A, Mahecha REG, Schaeffer R, Szklo A, Lucena AFP, Arango Aramburo S (2018) Fuel saving strategies in the Andes: long-term impacts for Peru, Colombia and Ecuador. Energ Strat Rev 20:35-48. https://doi.org/10. 1016/J.ESR.2017.12.011

16. Carvajal PE, Anandarajah G, Mulugetta Y, Dessens O (2017) Assessing uncertainty of climate change impacts on long-term hydropower generation using the CMIP5 ensemble-the case of Ecuador. Clim Chang 144:611-624. https://doi.org/10.1007/s10584-017-2055-4

17. Escribano G (2013) Ecuador's energy policy mix: development versus conservation and nationalism with Chinese loans. Energy Policy 57:152-159. https://doi.org/10.1016/j.enpol.2013.01.022

18. Vernengo M (2006) Technology, finance, and dependency: Latin American radical political economy in retrospect. Rev Radic Polit Econ 38:551-568. https://doi.org/10.1177/0486613406293220

19. Omeje K (2017) Extractive economies and conflicts in the global south: reengaging rentier theory and politics. InExtractive Economies And Conflicts In The Global South, Routledge, pp 19-44

20. Smith A, Stirling A, Berkhout F (2005) The governance of sustainable sociotechnical transitions. Res Policy 34:1491-1510. https://doi.org/10.1016/j. respol.2005.07.005

21. Huitema D, Lebel L, Meijerink S (2011) The strategies of policy entrepreneurs in water transitions around the world. Water Policy 13:717733. https://doi.org/10.2166/wp.2011.107

22. Scholz RW (2017) The normative dimension in transdisciplinarity, transition management, and transformation sciences: new roles of science and universities in sustainable transitioning. Sustain 9:991 internal-pdf://228.60. 152.102/Scholz Normativity Transdisciplinarity Transit.pdf

23. T.A.L. Berman, When knowledge is power: grassroots participatory initiative as a process of resource development, urban growth 2018. (2018)

24. Schäpke N, Omann I, Wittmayer JM, van Steenbergen F, Mock M (2017) Linking transitions to sustainability: a study of the societal effects of transition management. Sustain 9:737

25. Wallerstein I (1976) Semi-peripheral countries and the contemporary world crisis. Theory Soc 3:461-483. https://doi.org/10.1007/BF00161293

26. Watts MJ (2016) Colonialism, decolonization, and neocolonialism. Int Encycl Geogr People Earth Environ Technol. https://doi.org/10.1002/ 9781118786352.wbieg0692

27. Baudrillard J (1988) Consumer Society, Jean Baudrillard Sel Writings, pp 29-56

28. P.H. Smith, C.J. Sells, Democracy in Latin America, Oxford University Press 2016

29. Mitchell T (2009) Carbon democracy. Econ Soc 38:399-432. https://doi.org/ $10.1080 / 03085140903020598$

30. De Graaff N (2011) A global energy network? The expansion and integration of non-triad national oil companies. Glob Networks 11:262-283. https://doi. org/10.1111/j.1471-0374.2011.00320.x

31. Berrios R, Marak A, Morgenstern S (2011) Explaining hydrocarbon nationalization in Latin America: economics and political ideology. Rev Int Polit Econ 18:673-697. https://doi.org/10.1080/09692290.2010.493733

32. CONSTITUCION DEL ECUADOR (2008) Constitución del Ecuador - 2008. Regist Of 449:67. https://doi.org/10.1017/CBO9781107415324.004

33. Burchardt HJ, Dietz K (2014) (Neo-)extractivism - a new challenge for development theory from Latin America. Third World Q 35:468-486. https:// doi.org/10.1080/01436597.2014.893488

34. Sierra JC (2016) Estimating road transport fuel consumption in Ecuador. Energy Policy 92:359-368. https://doi.org/10.1016/j.enpol.2016.02.008

35. Fontaine $\mathrm{G}$ (2011) The effects of governance modes on the energy matrix of Andean countries. Energy Policy 39:2888-2898. https://doi.org/10.1016/j. enpol.2011.02.064
36. Ansar A, Flyvbjerg B, Budzier A, Lunn D (2014) Should we build more large dams? The actual costs of hydropower megaproject development. Energy Policy 69:43-56 https://doi.org/10.1016/j.enpol.2013.10.069

37. Scholz RW, Steiner G (2015) The real type and ideal type of transdisciplinary processes: part I-theoretical foundations. Sustain Sci 10:527-544. https:// doi.org/10.1007/s11625-015-0326-4

38. Brandt P, Ernst A, Gralla F, Luederitz C, Lang DJ, Newig J, Reinert F, Abson DJ, von Wehrden H (2013) A review of transdisciplinary research in sustainability science. Ecol Econ 92:1-15. https://doi.org/10.1016/j.ecolecon.2013.04.008

39. Hadorn GH, Bradley D, Pohl C, Rist S, Wiesmann U (2006) Implications of transdisciplinarity for sustainability research. Ecol Econ 60:119-128

40. Jahn T (2008) Transdisciplinarity in the practice of research, Transdisziplinäre Forsch. Integr. Forschungsprozesse Verstehen Und Bewerten. Campus Verlag, Frankfurt/Main, Ger, pp 21-37

41. Popa F, Guillermin M, Dedeurwaerdere T (2015) A pragmatist approach to transdisciplinarity in sustainability research: from complex systems theory to reflexive science. Futures 65:45-56. https://doi.org/10.1016/j.futures.2014.02.002

42. Patterson J, Schulz K, Vervoort J, van der Hel S, Widerberg O, Adler C, Hurlbert M, Anderton K, Sethi M, Barau A (2017) Exploring the governance and politics of transformations towards sustainability. Environ Innov Soc Transitions 24:1-16. https://doi.org/10.1016/j.eist.2016.09.001

43. Thomas EF, McGarty C, Mavor KI (2009) Aligning identities, emotions, and beliefs to create commitment to sustainable social and political action. Personal Soc Psychol Rev 13:194-218. https://doi.org/10.1177/ 1088868309341563

44. Reicher S, Spears R, Haslam SA (2010) The social identity approach in social psychology, Sage Identities Handb, pp 45-62 internal-pdf://179.58.177.4/ Social identity chapter final.doc

45. Harris F, Lyon F (2013) Transdisciplinary environmental research: building trust across professional cultures. Environ Sci Pol 31. https://doi.org/10.1016/ j.envsci.2013.02.006

46. UN-Habitat, 18 - Urban Infrastructure and Basic Services (2015) Including energy. Habitat III Issue Pap 2015:0-9 https://www.habitat3.org/the-newurban-agenda/issue-papers

47. Barragán-Escandón A, Terrados-Cepeda J, Zalamea-León E, BarragánEscandón A, Terrados-Cepeda J, Zalamea-León E (2017) The role of renewable energy in the promotion of circular urban metabolism. Sustain 9: 2341. https://doi.org/10.3390/su9122341

48. Loorbach D, Rotmans J (2010) The practice of transition management: examples and lessons from four distinct cases. Futures 42:237-246. https:// doi.org/10.1016/j.futures.2009.11.009

49. Pohl C, Hadorn GH (2008) Core terms in transdisciplinary research. Handb Transdiscipl Res:427-432

50. Geels FW (2002) Technological transitions as evolutionary reconfiguration processes: a multi-level perspective and a case-study. Res Policy 31:1257-1274

51. Suchman MC (1995) Managing legitimacy: strategic and institutional approaches. Acad Manag Rev 20:571-610

52. Kemp R, Loorbach D, Rotmans J (2007) Transition management as a model for managing processes of co-evolution towards sustainable development. Int J Sust Dev World 14:1-15

53. Upham P, Virkamäki V, Kivimaa P, Hildén M, Wadud Z (2015) Socio-technical transition governance and public opinion: the case of passenger transport in Finland. J Transp Geogr 46:210-219. https://doi.org/10.1016/j.jtrangeo.2015.06.024

54. F.W. Geels, J. Schot, Typology of sociotechnical transition pathways, 36 (2007) 399-417. doi:https://doi.org/10.1016/j.respol.2007.01.003

55. Lang DJ, Wiek A, Bergmann M, Stauffacher M, Martens P, Moll P, Swilling M, Thomas CJ (2012) Transdisciplinary research in sustainability science: practice, principles, and challenges. Sustain Sci 7:25-43. https://doi.org/10. 1007/s11625-011-0149-x

56. C. Ministerio de Energía, Energía 2050, (2016). http://www.energia2050.cl/ en/. Accessed 12 Sept 2018

57. Iniciativa Escenarios Energéticos Argentina 2035, Escenarios Energéticos Argentina 2035, (2015). http://wnw.escenariosenergeticos.org/. Accessed 12 Sept 2018 